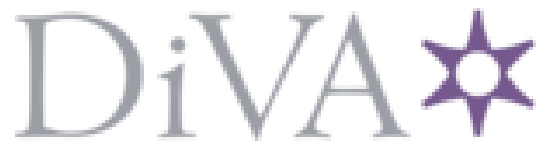

http://www.diva-portal.org

Postprint

This is the accepted version of a paper presented at 2017 EcoDesign.

Citation for the original published paper:

Gould, R K., Bratt, C., Lagun Mesquita, P., Broman, G I. (2017)

Integrating sustainable development and design-thinking-based product design.

In:

N.B. When citing this work, cite the original published paper.

Permanent link to this version:

http://urn.kb.se/resolve?urn=urn:nbn:se:bth-15656 


\title{
Integrating sustainable development and design-thinking-based product design
}

\author{
Rachael K Gould ${ }^{1}$, Cecilia Bratt ${ }^{1}$, Patricia Lagun Mesquita ${ }^{1}$, Göran I. Broman ${ }^{1}$ \\ ${ }^{1}$ Department of Strategic Sustainable Development, Blekinge Institute of Technology, Sweden.
}

\begin{abstract}
The aim of this research was to integrate sustainable development and design-thinking-based product design in order that the product design then contributes to society's transition to a sustainable future. This is an important pursuit since product lifecycles are a major cause of society's current sustainability challenges. To address this, many authors argue for integrating sustainable development into existing design processes rather than developing stand-alone tools and methods.

Through action research with a design consultancy who wanted to start working with sustainable product design, we iterated between three stages: understanding needs, designing action, and trying out the action. The first stage comprised document analysis, focus-group style workshops, a survey and interviews. When designing the actions (enhancements to their design-thinking-based process), we drew on literature on sustainable product design, decision-making for sustainability, and organisational learning and change for sustainability. We also drew on our research partners' practical experience. The enhanced process was tried out and further developed through feedback, student testing and co-development meetings.

The result is an enhanced process where project teams (i) use the outcomes from the inspiration phase of the existing process to choose sustainable design strategies that are relevant for their particular project. Once the teams have chosen which strategies to work with, for example, design for remanufacture, we suggest that they (ii) use the strategies to develop ideation foci/questions that help them explore the design space. The third enhancement is for teams to (iii) compare concepts with respect to sustainability as part of their concept comparison and evaluation.
\end{abstract}

Keywords:

Ecodesign; sustainable product design; design thinking; product development.

\section{INTRODUCTION}

"We can't solve problems by using the same kind of thinking we used when we created them" is a quote often attributed to Einstein. In this study, we explore a relatively new way of thinking - design thinking - to address the problem of unsustainable product lifecycles.

\subsection{Motivation}

Why product design?

Product lifecycle impacts are a major contributor to many of society's environmental and social challenges [1][2][3], and thus a problem worthy of our attention. Sustainable product development is also a means for companies to become and remain competitive [4][5].

Why integrate?

Integrating sustainable development with existing product design processes and practices is critical for successful implementation of sustainable product design [6][7]. Even the international standard ISO14006:2011, describes sustainable product design as involving the integration of sustainability considerations into product design. We therefore describe 'sustainable product design' as the integration of (i) sustainable development and (ii) design processes and practices - such that the product design helps society to transition to a sustainable future.

Why project teams need help?

Project teams need help with the integration of sustainable development and product design. The nature of sustainability is complex; it relates to social and ecological systems [8], and includes considering not only current global issues, but also potential future issues. Unsustainability can also be experienced as distant, in time and in space [9]. Wrestling with the complexity of sustainability is relatively new for product developers, compared to what they usually include in their decisionmaking. This novelty and complexity makes for tough decision-making conditions [10]. In particular, bringing a sustainability perspective to new product development “complicates an already complex process” [11](pg 106).

Why customise?

Since product development processes are unique to each company (even if they have similarities), the integration with sustainable development needs to be customised [12]. According to European ecodesign practitioners, a challenge with existing suggestions is that they are often not tailored to the business needs [13][12]. One-size-fits-all approaches 
for modelling the product design process ignore important aspects of reality [14]. Salerno et al. [14] identified 6 types of innovation process, and Gericke and Blessing [15] identified multiple significant ways to differentiate between processes. Several other authors have demonstrated their disillusionment with one-size-fits-all approaches to product design [14] (for example, [16] and [17]). Even if we were to try to integrate sustainable development with a generic, discipline-independent design model, generic models are too abstract to provide effective support for project teams [15] and thus our contribution would unlikely be effective. We therefore focused on a specific product design process.

Why design thinking?

One popular type of process is 'design-thinking'-based product design. Design thinking prioritises grounding design decisions in a thorough understanding of user needs, uses iterative prototyping and problem-solving to explore wicked problems, and employs divergent-convergent thinking [18]. Since design thinking was created to design in complexity, with an optimistic solution-expecting nature and diversity in project teams, it is a relevant process to explore from a sustainable development perspective [19]. Design thinking is optimised for breakthrough innovation (rather than incremental innovation) [18], which means that project teams are not locked into a particular (physical) solution and so the potential for impact is large. In fact, design thinking focuses on the needs of the user and delivering a functional result that addresses these needs, which is critical when designing sustainable solutions (with some mix of physical artefact and intangible service) [20].

\section{Research question}

Based on the above, we joined with an innovation consultancy to define the following research question, aiming to be relevant for both academia and practitioners.

\section{RQ: How might project teams that use a design- thinking-based product design process start to integrate sustainable development into their work?}

\subsection{Previous studies \& the gap}

During our study, The Ellen MacArthur Foundation and IDEO $^{1}$ jointly launched the 'circular design guide'. This is a design guide where circular design has been integrated with (a simplified version of) IDEO's design thinking process. There are currently no academic studies behind this guide, nor on its implementation. It will be interesting to follow its development and compare with our findings.

\section{PARTICIPATORY ACTION RESEARCH}

The research question is grounded in a desire to enhance practice, which is in line with the purpose of sustainability science to be solutions-orientated [21][22] . We therefore chose (together with some research participants from the company) to engage in action research due to its inherent intention to improve practice. In particular we chose the type of action research that is participative knowledge construction. This combines action research with collaborative methods for constructing knowledge together with those immediately affected (participatory research), in line with what Bergold and Thomas [23] call participatory action research and Greenwood and Levin [24] call pragmatic action research. The people who are immediately affected are knowing subjects, participants, rather than objects of the research. In our case, the participants are employees of a product innovation consultancy that uses a design-thinking-based product innovation process.

Our action research consisted of iteratively completing the cycle shown in figure 1 . The cycle comprises three notwholly-distinct phases and we completed three iterations. The description here is a simplification in order to aid communication of what was a very iterative and alive process, complicated with the messiness of reality.

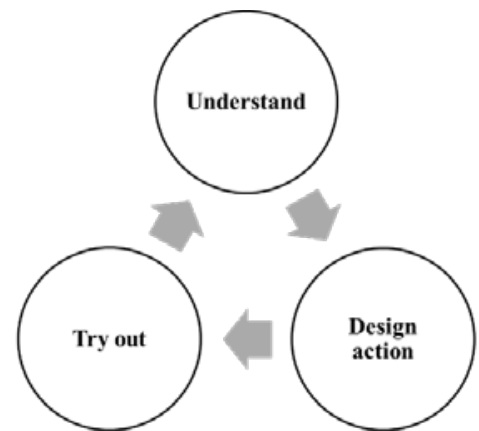

Fig. 1: Action research cycle of three not-wholly-distinct phases.

\subsection{Understanding}

The purpose of the understand phase was to increase collective understanding of relevant academic fields and of the current industrial practices, and associated challenges. In addition, the purpose of this phase in the second and third iterations was to also incorporate understanding of the results of previous 'try out action' phases.

In order to meet the above purposes, the academic researchers reviewed literature on sustainable product design, product development, decision-making for sustainability and organisational learning and change, as well as the intersections between these areas. In order to increase understanding of the processes and practices of the project teams that use the design-thinking-based product process, we used the following data collection methods: briefings by both sides - preparatory work that help set the scene for greater levels of participation (in line with Bergold \& Thomas [23]); interviews with practitioners on their practices and perspectives; collection of process and methods documents; observations during interactions; survey of employees; participants describing their own needs in meetings and emails; and a focus-group style workshop for exploring needs, which is "one of the key instruments for the creation of a 'communicative space'” ([23] sec 4.4). In order to increase understanding of the challenges that employees perceive in the integration with

\footnotetext{
${ }^{1}$ A design consultancy. See ideo.org.
} 
sustainable development, we used the following data collection methods: interviews; observations during meetings, workshop, evening course; and employee survey. The outcome of this phase was understanding of the needs (for action) described in sections 3.1 and 3.3. With each iteration, our understanding became more comprehensive.

\subsection{Designing action}

The purpose of the second phase was to use the understanding from the previous phase to co-design actions (enhancements to process and practice). We have thus far completed this phase three times, resulting in three versions (v1, v2 and v3). The first version was at the overview level, for which we actually designed two prototypes to be compared. Generating and comparing alternatives can help reduce the effects of confirmation bias [25][26] and evaluability bias [10], and leads to better designs [27], higher success rates in decision-making [28][29] and even quicker decision-making [30].

In order to design the enhanced process, we generated ideas on how to address the identified needs. We fuelled our ideation by reading literature on how others have solved similar problems. For example, literature on supporting decision-making for sustainability in other contexts.

\subsection{Trying out action}

The purpose of the third phase was to try out the designed actions and gather data on how it went and what could be improved. In the first iteration, we compared the pros and cons of the two alternatives in joint academics-practitioners meetings and via email. Data was collected data through: observations during meetings; and emails.

In the second iteration, we collected observations during a teaching session with product developers. In this iteration, the academic researchers also went outside of the partner company and tested the suggestions with product development students. Data was collected through: observations during class when they were using the suggestion, students' reflections after using the suggestion, and the outcomes from them using the suggestion.

In the third iteration, we discussed the workability of the suggestion - the adequacy of the suggestion according to how well it works in the local context [24]. In line with pragmatic action research (see [24] and [23]), we adopted the view that different participants may have different perspectives on what is adequate/good, and so the academic researchers first asked the practitioners to think about their views on what it means for them for the suggestion to work well, before commenting on the suggestion itself.

\subsection{Ethical considerations}

Key principles of action research are that democracy is a pre-requisite and that a safe space where participants can be open and show dissent needs to be developed [23][24]. Although building trust can take time, we believe that we have been fairly successful in creating this space and a power-equality between academic and practice-based knowledge since participants have been open with both positive and negative comments and even emotional sharing of frustrations.

All survey and interview data was handled anonymously. This paper was reviewed by a company representative before being submitted.

\subsection{Credibility of the research design}

The selection of action research as an approach and the toplevel design was made jointly by researchers and company participants. In action research, it is not a matter of standardizing methods, but rather choosing methods appropriate to the participants [23]. Many of the methods that we started out with are not especially participatory, for example, interviews. However, the interviews and surveys were research techniques that were familiar to the participants and therefore served both as a knowledge building step (for all involved) and for constructing the safe space and trust necessary for the later use of more participatory methods.

The iterative nature of our research and the multiple data collection methods and sources give us confidence in our results. In future research, we intend to extend this further to include many more participants. In particular, the lack of testing at the partner company on a real, live project is a weakness that we will address as soon as possible.

\section{RESULTS}

In this section, we describe the needs at a high-level before giving an overview of our suggestion. Then we dive into more detail, first on the needs and then on the suggested process enhancements.

\subsection{High-level description of needs}

We identified the following needs:

(A) Target the early phases of product development. These phases are a leverage point for integrating sustainability since the early-phase decision-making influences the sustainability impacts of manufacturing, as well as other lifecycle phases [31]. Decisions in the early phases also determine, to a large extent, the success of a project [32] and significantly impact development costs [33].

(B) Follow a value-focused approach. One empirical insight of the study was the difficulty in navigating the complexity of the decision-making context. Emphasizing values and value-trade-offs helps decision-makers to navigate this and focus on the sustainability considerations that matter for the project [34]. This can be achieved by fully investigating what is valued before exploring alternatives [35].

Considering how sustainability performance is valued and wanted would help project teams to make decisions that would likely deliver both business and societal benefits. This is in line with strategic sustainable development thinking (see [8]) as well as the shift in sustainable design research from trying to propose detailed and exhaustive support to proposing strategies that consider the 
opportunities and limitations of the business world [36] and have a more explicit focus on the strategic implementation of sustainable product design [37]. A value-focused approach may help in avoiding one of the main critiques of earlier sustainable product design suggestions - critique that there was not a strong enough link between strategic intent and content of the suggestion [6] and also avoid the implementation barriers that arise from scepticism for return-on-investment of sustainability initiatives [38].

(C) Focus on supporting the decision-making process, and not only on supporting analysis. The quality of the decisionmaking process (including exploiting analysis and reaching a decision) can be 6 times as important as the quantity and detail of analysis performed [39]. A good process also helps avoid poor analysis [39].

(D) Vary according to type of decision-making activity and use specific techniques to mitigate for cognitive illusions. Cognitive illusions lead to a perception, judgement or memory that deviates from 'reality' [40]. Cognitive illusions can also be known as biases [41]. Cognitive illusions likely occur in the tricky decision-making environment of starting to include sustainability considerations in product design. In order to mitigate for cognitive illusions, suggestions should vary with the type of activity [10], such as diverging and converging, including product development decision-making [42].

(E) Be simple enough to be practically usable by product design teams. Research participants frequently emphasised the need for the tools to be highly usable by sustainable design novices. In fact, one barrier to uptake of sustainable product design is that many tools are complicated and timeconsuming [43], and according to European ecodesign practitioners, overly complex [13]).

(F) Assist project teams to learn about sustainable development and develop tacit knowledge on doing sustainable design. The human side, or 'soft side', of sustainable design is important [44] and insights from other disciplines (such as organisational learning [7]) are needed for understanding this side [45][46]. Knowledge and skills in sustainable design within the organisation is one of the two categories of internal company barriers to sustainable product development (for small-to-medium enterprises) [48]. Capability of the designers and engineers, in terms of knowledge, skills and decision-making power, is a success factor in sustainable design implementation [38][43][48].

\subsection{Overview of suggested enhancements}

The existing product design process at the partner company is based on design thinking similar to that used by IDEO (ideo.org). The IDEO process comprises three phases: investigating the challenge and the needs of the people involved (inspiration phase); generating ideas, identifying opportunities and prototyping (ideation phase); and bringing the concept to life and selling it (implementation phase). This process involves many iterations between convergent and divergent thinking. The ideation phase of the partner company's process comprises three sub-phases
- strategy, ideas and concept. (Their concept sub-phase includes a little more convergence than is apparent in IDEO's model.)

In order to meet the needs identified in the previous subsection, we suggest that the company enhances the ideation sub-phases with the activities shown in figure 2 . The key principle behind the suggestion is that the project team chooses between different ways to work with sustainability during the ideation phase, according to what is relevant for their project. These enhancements will be specified in more detail in later subsections.

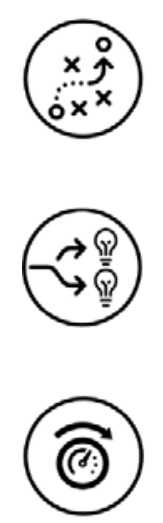

\section{STRATEGY}

Choose sustainable product design strategies relevant to the project.

\section{IDEAS}

Apply the strategies to generate ideas for sustainable products.

\section{CONCEPT}

Compare concepts with respect to sustainability.

Fig. 2: Overview of suggested sustainability enhancements.

In the strategy sub-phase, project teams use their knowledge from the inspiration phase to choose sustainable product design strategies that are relevant to their project. These strategies offer ways to ideate for sustainability, with each strategy doing so from a different perspective. Example strategies include design for remanufacture and design for the base of the pyramid. Through deciding what is relevant to their current project, project teams are identifying leverage points, as recommended by Shapira et al. [19] and can work with sustainability in a way that matches the project goals, including business goals. Choosing between ways to work with sustainability is also appropriate because different projects have different possibilities for sustainable product design. For example, designing electrical equipment (with slower innovation cycles, common materials, and well-known use scenarios) is a very different context with different possibilities for sustainable design than designing electronic equipment (with shorter innovation time, specialised materials and evolving usage) [49]. In addition, the team chooses sustainable product design strategies at the same time as choosing other strategies, such as the overall marketing strategy. This is in line with how companies seem to prefer to complement existing operations strategies, rather than creating sustainability-specific ones [50]. A sentiment shared by the partner company.

\subsection{Detailed needs - required functions}

Given the overall suggestion shown in figure 2, we now explain some of the detailed needs that we uncovered. 
Expanding on need (D) - when project teams are choosing strategies and selecting concepts - the suggested process enhancements should help project teams to mitigate for cognitive illusions by facilitating them to [42]:

(Di) emphasise values and value trade-offs (related to need (B)),

(Dii) check that the alternatives are credible,

(Diii) use ends-objectives instead of means-objectives,

(Div) compare alternatives rather than considering each option in isolation,

(Dv) make it as easy to evaluate with respect to sustainability as for other aspects,

(Dvi) prioritise searching for key knowledge,

(Dvii) use a diagnostic strategy to mitigate for confirmation bias,

(Dviii) scrutinise where information came from,

(Dix) search for evidence of the unexpected,

(Dx) frame analysis results in multiple ways, and

(Dxi) ask themselves if they are being overly cautious.

Also expanding on need (D) -when project teams are employing the strategies to generate ideas - the suggested process enhancements should help project teams to mitigate for cognitive illusions by [42]:

(Dxii) employing passive decision-support techniques,

and facilitating project teams to [42]:

(Dxiii) generate alternatives that are meaningfully different from each other,

(Dxiv) include stakeholder perspectives, and

(Dxv) use a diagnostic strategy.

(Dxiv) was also a strong desire from those responsible for the design process in the partner company, probably because of the central role that understanding stakeholder perspectives plays in design thinking.

Research on the human side has started to converge on some general principles, including (1) the transformative nature of sustainable product design and (2) the need to include both organisational and individual dimensions [51]. Using Lam's [52] model for organisational learning, need (F) can be expanded in two dimensions individual/collective and explicit/tacit - as follows. In order for the organisation to learn and develop (in terms of sustainable design knowledge), individual project team members need to learn:

(Fi) embrained (formal, abstract) knowledge, through formal instruction;

(Fii) embodied (context-specific bodily) knowledge, through direct interaction and mutual adjustment during practical experience in a relevant context.

Similarly, teams need to learn:

(Fiii) encoded knowledge (selected, simplified knowledge coded into rules and procedures);

(Fiv) embedded knowledge (norms and shared beliefs that can support complex interaction patterns), through multi-functional team practical experience in a relevant context.

Learning may lead to attitude changes, which is important because one of the key challenges for ecodesign implementation in companies is people's attitudes [47]. It is not so surprising that attitudes are not always conducive to sustainable design implementation since unsustainability can be experienced as distant, in time and in space and the communicating climate disruption (see [9]), in order to avoid emotive and political nature of sustainable development can even lead to individuals experiencing discomforting dissonance [9]. Taking tips from the science of psychological barriers in sustainability communication and to encourage action, instructions and support should:

(Fv) use the power of the social nature of humans,

(Fvi) be framed positively (showing opportunities, rather than just what to avoid), and

(Fvii) be easy and convenient to employ.

(Fvi) and (Fvii) were also strongly supported by our empirical studies. The above detailed needs are, of course in addition to the high-level needs (A), (B), (C) and (E).

\subsection{Details of suggested enhancements \\ Choosing strategies}

In the strategy sub-phase, when project teams are answering other questions about strategy, we suggest that they also ask themselves the following: Which sustainable design strategies shall we employ? Which will likely deliver value for this project? To aid with this, we have prepared the instructions shown on the left-hand side of figure 3 .

The strategy comparison table is a decision support prototype designed to help project teams to choose between strategies. It provides information on both potential business value that can be achieved by applying the strategy and potential sustainability value, in line with the prioritisation guidelines used in the framework for strategic sustainable development (see [8]). This prototype was developed as part of our project since a high number of strategies exist and it is difficult to select the most appropriate one(s) [36]. When using the prototype, project teams will hopefully learn about sustainability, as defined in the framework for strategic sustainable development and make a choice while understanding what aspects of sustainability and which lifecycle stages they are not yet addressing. See [53] for details of the prototype.

\section{Applying strategies}

In the ideas sub-phase, when project teams are ideating, we suggest that they ideate also around the chosen sustainable product design strategy(ies). See the right-hand side of figure 3 for the instructions for project teams.

Comparing concepts with respect to sustainability

We have not focused on support for comparing and selecting concepts since there is much existing support, even support based on the same definition of sustainability.

\subsection{Evaluation and results from trying out}

Looking at the identified needs, our overall suggestion is value-focused $\left(B^{\checkmark}\right)$ and addresses the early phases (A $\checkmark$ ). We suggest process-centric enhancements $(C \checkmark)$, such as how to gather information. As is evident from figure 3 , the suggestions do vary with type of decision-making activity (selection / ideation) (D $\checkmark$ ), and most of the detailed needs have been addressed. Future work should investigate how 


\section{How to choose:}

\section{Explore relevance}

Using the strategy comparison table, write down the pros and cons of each strategy for your

particular project. Imagine that you are explaining

to your client how each strategy is relevant and not relevant to their particular needs.

\section{Check your assumptions}

Check your assumptions or unknowns. This is important since this is an area that you are unfamiliar with. Search for evidence that supports what you have written as pros and cons. Search also for information that supports the opposite of what you have written as pros and cons. Adjust your pros and cons accordingly.

\section{Choose \& justify}

Write down your choice of strategy and justify why you chose this/these strategy/strategies over the other strategies.

\section{EXTRA TIPS}

Nobel prize-winning decision science researcher Kahneman, and his colleagues, suggest asking yourself, "If you had to make this decision again in a year's time, what information would you want, and can you get more of it now?

\section{How to apply:}

\section{Strategy to questions}

Using the info on each strategy to design ideation ("How might we...") questions.

\section{Ideate as usual}

Use usual methods and tools for ideation around each of the ideation questions.

\section{Combine ideas and iterate}

As usual, combine ideas and iterate. Combine ideas from the various HMW questions, from across the chosen strategies and from the ideation session. Combine and iterate, as usual, until you have many product concepts.

\section{EXTRA TIPS}

Consider when to ideate around a given strategy. For example, 'PSS design for sustainability should be one of the earlest ideation sessions, whe 'Design for sustainable behaviour' can be used

later. Of course, best practice is to iterate and seek to combine ideas from various ideation sessions.

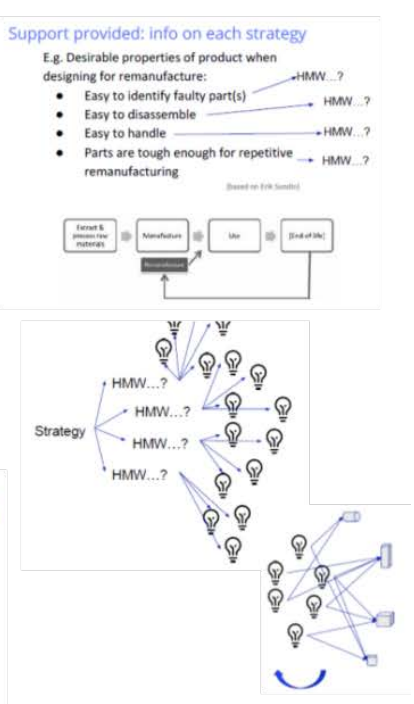

Fig. 3: Suggested enhancements to the strategy and ideas sub-phases - instructions to project teams.

to encourage teams to involve sustainability stakeholders in their ideation (Dxiv).

The suggested enhancements are knowledge encoded in process format (Fii $\checkmark$ ) and they encourage the project teams themselves to learn tacit knowledge by taking practical step-by-step action (Fiii $\checkmark$ ). The suggestions also provide positive framing (Fvi $\checkmark$ ) by taking an opportunity-based perspective of sustainable design (which also aligns with design thinking). Although some formal instruction (Fi $\checkmark$ ) on sustainability and sustainable design is included in the suggestion (not shown in this paper), there is an opportunity for more. In fact, the partner company has asked for more.

During the first iteration, we learnt that it is better to integrate sustainable development in the methods used for generating ideas to address the customer needs (and choosing between ideas), rather than merely adding 'sustainability' as an additional need. The chosen approach received a positive and energetic response in the teaching session with product developers (second iteration). Reflecting on the suggestion, one (heavily involved) research participant wrote "I realise that we are completely right with this... [it is] something that I definitely think that we should work with". These responses give indications of the workability of the suggestion. During the second iteration, we learnt much about gaps in the usability ( $\mathrm{E}$ and Fvii) of our suggestion when students struggled to understand parts of the instructions or used them in unexpected ways. These enhancements are included in the instructions shown in figure 3, which is our prototype v3.

\section{SUMMARY}

We have outlined the needs of project teams that use a design-thinking-based product design process and who want to start to integrate sustainable development into their work. To address these needs, we have suggested enhancements to a design-thinking-based product design process that project teams can use to start to integrate sustainable development their work. Through our action research project, we learnt that:

It is better to integrate sustainable development with the process used for generating ideas to address customer needs (and choosing between ideas), rather than merely adding 'sustainability' as an additional need.

Sustainable development should be integrated into the process such that teams are facilitated to work with sustainable design in a way that is relevant to their particular project (industry, market, customer needs) while also better understanding the advantages and limitations of that chosen way. This is in line with the purpose of design thinking to address complex problems, and also supports stronger competence development in the project team.

The suggested enhancements can now be tested by others using a design-thinking-based product design process, as well as by the partner company on a real project.

\subsection{Contribution}

Our contribution to research is not just another tool, which is a problem with research in the field that was identified already in 2002 [6], but enhancements to a design process 
that help project teams to make sense of and choose between existing strategies for sustainable product design. Our contribution to practice is suggested enhancements that are designed to be, not just academically credible, but also practically relevant through integration in an existing process and customizability. Our suggestions address a gap in support for those working with design thinking. We found no equivalent studies and thus argue originality.

\section{REFERENCES}

[1] Kaebernick, H., Kara, S., \& Sun, M. (2003). Sustainable product development and manufacturing by considering environmental requirements. $R O B O T$ CIM-INT MANUF, 19(6), 461-468.

[2] Pujari, D. (2006). Eco-innovation and new product development: Understanding the influences on market performance. TECHNOVATION, 26(1), 7685.

[3] Tukker, A., \& Jansen, B. (2006). Environment impacts of products - A detailed review of studies. $J$ IND ECOL, 10(3), 159-182.

[4] Pujari, D., Wright, G., \& Peattie, K. (2003). Green and competitive: Influences on environmental new product development performance. $J$ BUS RES, 56(8), 657-671.

[5] Dangelico, R. M., \& Pujari, D. (2010). Mainstreaming green product innovation: Why and how companies integrate environmental sustainability. J BUS ETHICS, 95(3), 471-486.

[6] Baumann, H., Boons, F., \& Bragd, A. (2002). Mapping the green product development field: engineering, policy and business perspectives. J CLEAN PROD, 10(5), 409-425.

[7] Brones, F., \& de Carvalho, M. M. (2015). From 50 to 1: integrating literature toward a systemic ecodesign model. J CLEAN PROD, 96, 44-57.

[8] Broman, G. I., \& Robert, K.-H. (2017). A framework for strategic sustainable development. J CLEAN PROD, 140, 17-31.

[9] Stoknes, P. E. (2014). Rethinking climate communications and the "psychological climate paradox”. Energy Research \& Social Science, 1, 161170.

[10] Arvai, J., Campbell-Arvai, V. \& Steel, P. (2012). Decision-making for sustainability: A systematic review of the body of knowledge. Network for Business Sustainability, Ontario. Available online: http://nbs.net/knowledge/business-case/decisionmaking/systematic-review/.

[11] Goffin, K. (2012). Sustainability and new product development. Cranfield on Corporate Sustainability, 105-118.
[12] Knight, P., \& Jenkins, J. O. (2009). Adopting and applying eco-design techniques: A practitioners perspective. J CLEAN PROD, 17(5), 549-558.

[13] Prendeville, S., Niemczyk, M., Sanders, C., Lafond, E., Elgorriaga, A., Mayer, S., \& Kane, D. (2013), Motivations for and Barriers to Ecodesign in Industry. Available online: http://cloud.snappages .com/b0d6d10923becba07c0287d0b0af8fd47ed8a57 d/ENEC_motivations\%20\&\%20barriers.pdf

[14] Salerno, M., Gomes, L., da Silva, D., Bagno, R., \& Freitas, S. (2015). Innovation processes: Which process for which project? TECHNOVATION, 35(1), 59-70.

[15] Gericke, K. \& Blessing, L. (2012). An analysis of design process models across disciplines. In: DESIGN 2012, Conference, Dubrovnik, Croatia.

[16] Shenhar, A. J. (2001). One size does not fit all projects: exploring classical contingency domains. MANAGE SCI. 47(3), 394-414.

[17] Sauser, B. J., Reilly, R. R., \& Shenhar, A. J. (2009). Why projects fail? How contingency theory can provide new insights - A comparative analysis of NASA's mars climate orbiter loss. INT $J$ PROJ MANAG, 27(7), 665-679.

[18] Fleury, A., Stabile, H., \& Carvalho, M. (2016). An overview of the literature on design thinking: Trends and contributions. INT J ENG EDUC, 32(4), 17041718.

[19] Shapira, H., Ketchie, A., \& Nehe, M. (2017). The integration of design thinking and strategic sustainable development. J CLEAN PROD, 140, 277287.

[20] Thompson, A. W. (2012). Integrating a strategic sustainable development perspective in productservice system innovation $\mathrm{PhD}$ Thesis: School of Engineering, Blekinge Institute of Technology.

[21] Miller, T. R. (2013). Constructing sustainability science: Emerging perspectives and research trajectories. Sustainability Science, 8(2), 279-293.

[22] Miller, T. R., Wiek, A., Sarewitz, D., Robinson, J., Olsson, L., Kriebel, D., \& Loorbach, D. (2014). The future of sustainability science: A solutions-oriented research agenda. Sustainability Science, 9(2), 239246.

[23] Bergold, J. \& Thomas, S. (2012). Participatory Research Methods: A Methodological Approach in Motion. Forum Qualitative Sozialforschung / Forum: Qualitative Social Research, 13 (1). Art. 30.

[24] Greenwood, D. J. \& Levin, M. (2006). Introduction to action research: Social research for social change. SAGE publications.

[25] Oswald, M. \& Grosjean, S. (2004). Confirmation bias. In: Cognitive illusions: A handbook on fallacies and 
biases in thinking, judgment and memory, ed. R. Pohl, 79-96. New York: Psychology Press.

[26] Kahneman, D., Lovallo, D., \& Sibony, O. (2011). Before you make that big decision. HARVARD BUS REV 89(6): 50-60.

[27] Dow, S., Glassco, A., Kass, J., Schwarz, M., Schwartz, D., \& Klemmer, S. (2010). Parallel prototyping leads to better design results, more divergence, and increased self-efficacy. ACM TOCHI, 17(4), 1-24.

[28] Nutt, P. C. (1999). Surprising but true: Half the decisions in organizations fail. ACAD MANAG EXEC J, 13(4), 75.

[29] Gemünden, H. G., \& Hauschildt, J. (1985). Number of alternatives and efficiency in different types of topmanagement decisions. EUR J OPER RES, 22(2), 178-190.

[30] Eisenhardt, K. M. (1989). Making fast strategic decisions in high-velocity environments. ACAD MANAG J, 32(3), 543-576.

[31] Bhamra, T. A., Evans, S., McAloone, T. C., Simon, M., Poole, S., \& Sweatman, A. (1999). Integrating environmental decisions into the product development process. I. The early stages. Proceedings EcoDesign'99, 329-333.

[32] Martinsuo, M., \& Poskela, J. (2011). Use of evaluation criteria and innovation performance in the front end of innovation. J PROD INNOVAT MANAG, 28(6), 896914.

[33] Ulrich, K. T., \& Eppinger, S. D. (2012). Product design and development ( $5^{\text {th }}$ International ed.). London: McGraw-Hill Higher Education.

[34] Keeney, R. L. 1992. Value focused thinking: A path to creative decision making. Harvard University Press.

[35] Gregory, R., L. Failing, M. Harstone, G. Long, T. McDaniels \& Ohlson, D. (2012). Structured Decisionmaking: A practical guide to environmental management choices. UK: Wiley-Blackwell.

[36] Rossi, M., Germani, M., \& Zamagni, A. (2016). Review of ecodesign methods and tools. Barriers and strategies for an effective implementation in industrial companies. J CLEAN PROD, 129, 361-373.

[37] Pigosso, D., McAloone, T., \& Rozenfeld, H. (2015). Characterization of the state-of-the-art and identification of main trends for ecodesign tools and methods: Classifying three decades of research and implementation. J INDIAN I SCI, 95(4), 405-427.

[38] Short, T., Lee-Mortimer, A., Luttropp, C., Johansson, G. (2012). Manufacturing, sustainability, ecodesign and risk: Lessons learned from a study of Swedish and English companies. J CLEAN PROD, 37, 342352.

[39] Lovallo, D. \& O. Sibony, O. (2010). The case for behavioral strategy. McKinsey Quarterly (2) 30-43.
[40] Pohl, R. (eds) (2004). Cognitive illusions: A handbook on fallacies and biases in thinking, judgment and memory. New York: Psychology Press.

[41] Tversky, A. \& Kahneman, D. (1974). Judgment under uncertainty: Heuristics and biases. SCIENCE 185(4157) 1124-1131.

[42] Gould, R. K. \& Svensson, M. Sustainable product development and tricks on the mind. Submitted.

[43] Bovea, M. D., \& Pérez-Belis, V. (2012). A taxonomy of ecodesign tools for integrating environmental requirements into the product design process. $J$ CLEAN PROD, 20(1), 61-71.

[44] Boks, C. (2006). The soft side of ecodesign. $J$ CLEAN PROD, 14(15), 1346-1356.

[45] Boks, C., \& McAloone, T. C. (2009). Transitions in sustainable product design research. Int. J. of Product Development, 9(4), 429.

[46] Verhulst E., Boks C., Stranger M., Masson H. (2007) The Human Side of Ecodesign from the Perspective of Change Management. In: Takata S., Umeda Y. (eds) Advances in Life Cycle Engineering for Sustainable Manufacturing Businesses. Springer, London.

[47] Dekoninck, E., Domingo, L., O'Hare, J., Pigosso, D., Reyes, T., \& Troussier, N. (2016). Defining the challenges for ecodesign implementation in companies: Development and consolidation of a framework. J CLEAN PROD, 135, 410-425.

[48] O’Rafferty, S., \& O’Connor, F. (2010). Regional perspectives on capacity building for ecodesign insights from wales. In: Sarkis, J., Cordeiro, J.J. and Brust, D.A.V. (Ed.), Facilitating sustainable innovation through collaboration, Springer, Netherlands, pp. 159-183.

[49] Unger, N., Schneider, F., \& Salhofer, S. (2008). A review of ecodesign and environmental assessment tools and their appropriateness for electrical and electronic equipment. Progress in Industrial Ecology, 5(1-2), 13-29.

[50] Longoni, A., \& Cagliano, R. (2015). Environmental and social sustainability priorities: Their integration in operations strategies. INT J OPER PROD MAN, 35(2), 216-345.

[51] Brones, F., de Carvalho, M. M. \& de Senzi Zancul, E. (2017). Reviews, action and learning on change management for ecodesign transition. J CLEAN PROD, 142(1), 8-22.

[52] Lam, A. (2000). Tacit knowledge, organizational learning and societal institutions: an integrated framework. ORGAN STUD, 21(3), 487-513.

[53] Gould, R. K., Lagun Mesquita, P., Bratt, C., \& Broman, G. I.. (2017). Why choose one sustainable design strategy over another: A decision-support prototype. Proceedings ICED17, Canada, 5, 111-120. 